\title{
Tropical Journal of Pathology and Microbiology

\section{Tumors and tumor-like lesion of the oral cavity: A study of 100 cases at tertiary care hospital}

\author{
Rauf SPA. ${ }^{1}$, Sonwane BR. ${ }^{2 *}$ \\ DOI: https://doi.org/10.17511/jopm.2020.i04.01 \\ ${ }^{1}$ Shaikh Parvin Abdul Rauf, Post-graduate, Department of Pathology, Government Medical College and Hospital, Aurangabad, Maharashtra, \\ India. \\ 2* Bharat R Sonwane, Associate Professor, Department of Pathology, Government Medical College and Hospital, Aurangabad, Maharashtra, \\ India.
}

Introduction: Oral cancer is a major health problem in some parts of the world especially developing countries. Oral cancer is the sixth most common cancer in the world whereas in India it is the most prevalent cancer. In India increase in incidence is seen in states like Uttar Pradesh, Madhya Pradesh, Gujarat, Bihar, and Maharashtra. Material \& Methods: A total of 100 cases have been studied over a period of two years \& two months. The surgical pathology specimens received for histopathological diagnosis were examined microscopically, and the diagnosis was confirmed. Results: Amongst 100 cases studied, 72 (72\%) cases were malignant, 12(12\%) were benign, 12 $(12 \%)$ were tumor-like lesions and $4(4 \%)$ cases were premalignant conditions. The youngest patient was 4 years of age and the oldest of 84 years. The male: female ratio was2.3:1. Tobacco chewing was the commonest habit observed in patients with a malignant tumor. Buccal mucosa was the commonest site of tumors and tumor-like lesions. Conclusions: It is the need of the hour to create awareness among people about the early approach to hospital, maintenance of oral hygiene by cultivating good oral habits, and periodic oral check-ups.

Keywords: Oral cancer, Tobacco-related product, Tumors of the oral cavity

Corresponding Author

Bharat R Sonwane, Associate Professor, Department of Pathology, Government Medical College and Hospital, Aurangabad, Maharashtra, India. Email: bsonwane@gmail.com
How to Cite this Article To Browse Rauf SPA, Sonwane BR. Tumors and tumor-like lesion of the oral cavity: A study of 100 cases at tertiary care hospital. Trop J Pathol Microbiol. 2020;6(4):265-274.

Available From

https://pathology.medresearch.in/index.php/jopm/ar ticle/view/439

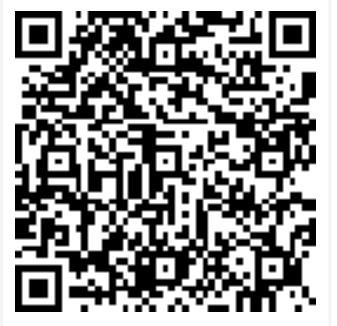

\section{Introduction}

Oral cancer is a major health problem in developing countries. Oral cancer is the sixth most common cancer in the world whereas, in India, it is the most prevalent cancer. Data from the National Cancer Registry, Indian Council of Medical Research has confirmed the
Manuscript Received 23-02-2020

Conflict of Interest No

Review Round 1
03-03-2020
Funding
Nil

$\mathrm{Nil}$

\section{Review Round 2 07-03-2020

Fact that oral cancer is the most common cancer in India. In India increase in incidence is seen in states like Uttar Pradesh, Madhya Pradesh, Gujarat, Bihar, and Maharashtra, In addition, the involvement of oral cavity in mastication makes it susceptible for different types of trauma and injury, also the presence of teeth and odontogenic tissue is adding

(c) 2020 by Shaikh Parvin Abdul Rauf, Bharat R Sonwane and Published by Siddharth Health Research and Social Welfare Society. This is an Open Access article licensed under a Creative Commons Attribution 4.0 International License https://creativecommons.org/licenses/by/4.0/ unported [CC BY 4.0].

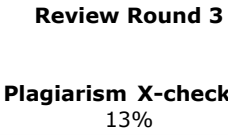
Note 
More liability for other groups of diseases which vary from simple inflammatory diseases to that highly malignant tumor $[1,2]$. Recent studies suggest that human papillomavirus may be associated with oral and oropharyngeal cancers [3].

Among oral cancer Squamous cell carcinoma accounts for $>90 \%$ of oral cancers attributing to risk factors like the habit of tobacco chewing, betel nut, and alcohol consumption [4]. Males are more commonly affected than females due to the habits of chewing tobacco, areca nut, betel quid, bidi, khaini, Gutkha, and alcohol [7,8].

Among premalignant conditions oral submucous fibrosis is most common due to habits of spicy foods $[4,7]$. Though the oral cavity is more accessible to complete examination, the disease gets detected in later stages either due to ignorance or inaccessibility to medical care [2]. The present study is undertaken at our institute, to find out the incidence of tumors and tumor-like lesions in the oral cavity

\section{Aims and Objectives}

To study the actual incidence, age and sex incidence and various histopathological appearance and patterns of tumors of the oral cavity, and their prognostic implications. To study the clinical presentation of the lesions, their various risk factors, and to correlate with histopathological diagnosis.

\section{Material\& Methods}

Study setting: The present study was conducted in the Department of Pathology, Government Medical College and Hospital, Aurangabad, Maharashtra. It is a tertiary care institute in the Marathwada region of Maharashtra which shares borders of Khandesh, Vidharba, and West Maharashtra. Patients from above neighboring borders are referred to our hospital for higher patients care.

Ethical consideration and permission: The institutional ethical committee and review board approval were obtained. In the present study, the participant was informed about the importance and written consent was taken.

Duration and type of study: The present study was conducted over a period of two years \& two months from July-2014 to Oct-2016.
Study subjects: The patients attending OPD having a tumor and tumor-like lesions of the oral cavity were included in the study.

Inclusion criteria: Patients above 18 years of age having tumor and tumor lesions and history of consumption of tobacco-related products.

Exclusion criteria: The Patients already diagnosed as tumors and tumor-like lesions of the oral cavity and dental lesions are excluded from the study.

Sampling: All the patients reporting during the study period and fulfilling the selection criteria were included in the study. A total of 100 cases were included.

Data collection procedure: The patients who were admitted in the wards for oral cavity lesions, the clinical assessment, nature, and extent of the lesion were studied in each case prospectively.

Sampling method: Relevant clinical details of cases and important results of investigations, with the detailed gross examination of the specimen, noted in proforma. The surgical pathology specimens received for histopathological diagnosis. Specimens received in the form of biopsy, surgical specimen, and reference slides. All biopsies were embedded completely after thorough gross examination, resected. The standard method of $\mathrm{H}$ and $E$ stains was performed and the sections were examined microscopically, the special stain has done wherever necessary, and microscopic examination findings were noted and histopathological diagnosis was confirmed.

\section{Results}

Among 100 cases studied, 72 (72\%) cases were malignant, 12 (12\%) were benign, 12 (12\%) were tumor-like lesions and $4(4 \%)$ cases were premalignant conditions (Figure 1 ).

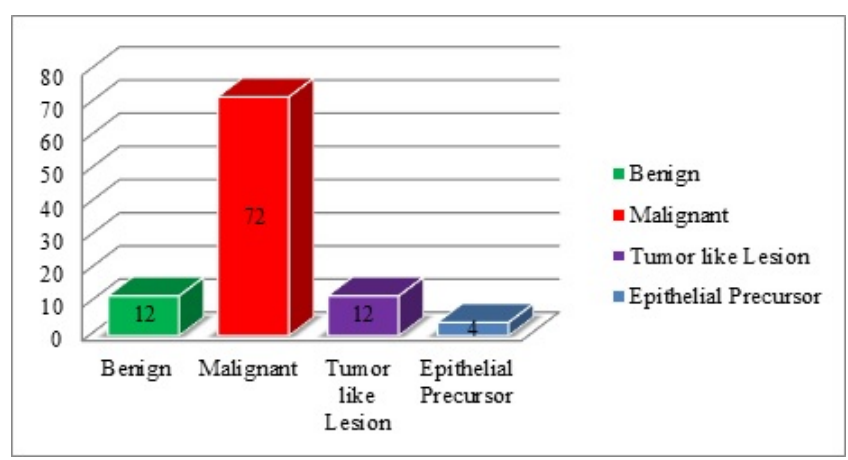

Fig-1: Distribution of tumors and tumor-like lesions of the oral cavity. 
Table-1: Age-wise distribution of tumors and tumor lesions of the oral cavity.

\begin{tabular}{|c|c|c|c|c|c|c|c|c|}
\hline \multirow[t]{2}{*}{ Age (Years) } & \multicolumn{2}{|c|}{ Malignant lesions } & \multicolumn{2}{|c|}{ Epithelial precursor lesions } & \multicolumn{2}{|c|}{ Benign lesions } & \multicolumn{2}{|c|}{ Tumor like lesions } \\
\hline & No. & Percent & No. & Percent & No. & Percent & No. & Percent \\
\hline $1-10$ & 02 & 2.78 & - & - & 01 & 8.33 & - & - \\
\hline $11-20$ & - & - & - & - & - & - & - & - \\
\hline $21-30$ & 01 & 1.39 & - & - & - & - & 04 & 33.33 \\
\hline $31-40$ & 05 & 6.9 & 01 & 25 & 04 & 33.33 & 02 & 16.67 \\
\hline $41-50$ & 15 & 20.83 & 02 & 50 & 04 & 33.33 & 05 & 41.67 \\
\hline $51-60$ & 27 & 34.72 & 00 & 00 & 03 & 25 & 01 & 8.33 \\
\hline 61-70 & 19 & 26.39 & 01 & 25 & 00 & 00 & - & - \\
\hline 71-80 & 02 & 2.78 & - & - & - & - & - & - \\
\hline $81-90$ & 01 & 1.39 & - & - & - & - & - & - \\
\hline Total & 72 & 100 & 4 & 100 & 12 & 100 & 12 & 100 \\
\hline
\end{tabular}

Table 1 represented among 100 cases studied age range was 4 years to 84 years. The youngest patient was 5 years of age and the eldest patient was 84 years old. Out of 100 cases, 70 (70\%) were male and 30 (30\%) were female with a male: female ratio being $2.3: 1$.

Table-2: Site distribution of tumors and tumor-like lesions of the oral cavity.

\begin{tabular}{|c|c|c|c|c|c|c|c|c|c|c|}
\hline \multirow[t]{2}{*}{ Site of lesion } & \multicolumn{2}{|r|}{ Malignant } & \multicolumn{2}{|c|}{ Epithelial Precursor } & \multicolumn{2}{|r|}{ Benign } & \multicolumn{2}{|c|}{ Tumour like } & \multicolumn{2}{|c|}{ Total } \\
\hline & NO & $\%$ & NO & $\%$ & NO & $\%$ & NO & $\%$ & No & $\%$ \\
\hline Buccal mucosa & 23 & 31.94 & 2 & 50 & 4 & 33.33 & 2 & 16.67 & 31 & 31 \\
\hline Tongue & 16 & 22.22 & 1 & 25 & 4 & 33.33 & 2 & 16.67 & 23 & 23 \\
\hline Floor of mouth & 4 & 5.55 & - & - & 1 & 8.33 & 1 & 8.33 & 6 & 6 \\
\hline Retromolar Trigone & 7 & 9.7 & - & - & - & - & 1 & 8.33 & 8 & 8 \\
\hline Lip & 8 & 11.11 & - & - & 1 & 8.33 & 3 & 25 & 12 & 12 \\
\hline Hard palate & 9 & 12.5 & - & - & 1 & 8.33 & 1 & 8.33 & 11 & 11 \\
\hline Gingiva & 5 & 6.9 & 1 & 25 & 1 & 8.33 & 2 & 16.67 & 9 & 9 \\
\hline Total & 72 & 100 & 4 & 100 & 12 & 100 & 12 & 100 & 100 & 100 \\
\hline
\end{tabular}

Table 2 represented, Out of 72 malignant lesions in the present study, in 23 cases (31.94\%) buccal mucosa was the commonest site. Gingiva and floor of mouth were the least involved sites in the present study.

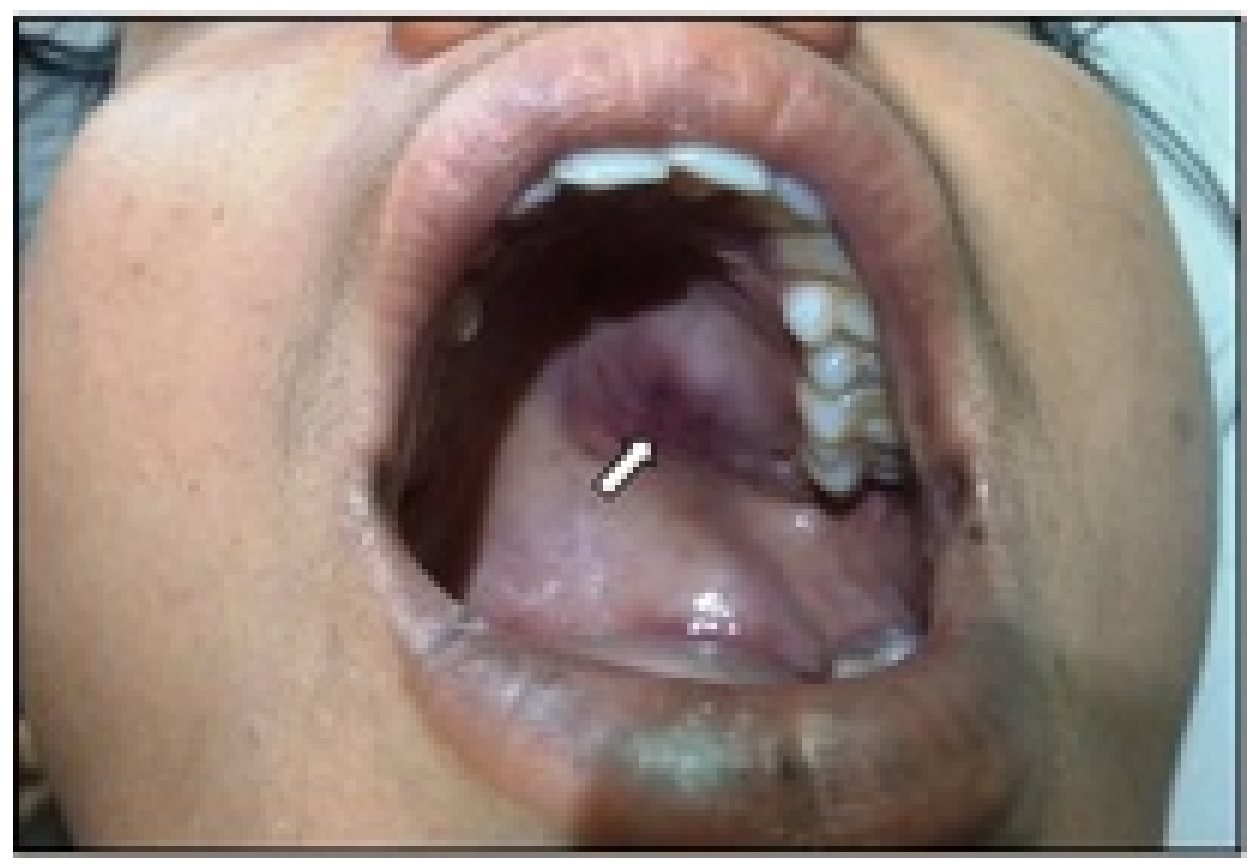

Fig-2: Photograph showing mucoepidermoid carcinoma presenting on the hard palate. 


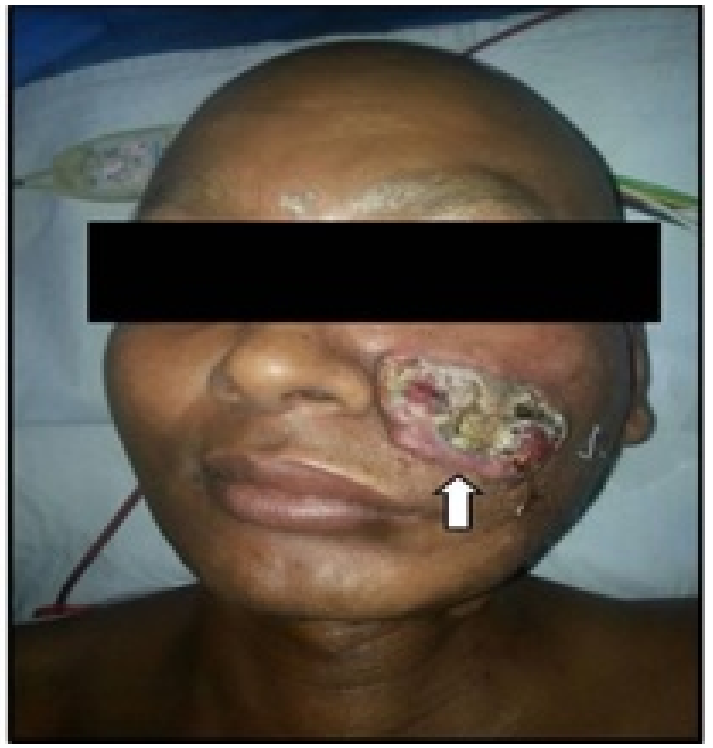

Fig-3: Photograph showing ulcer-proliferative lesion over the cheek.

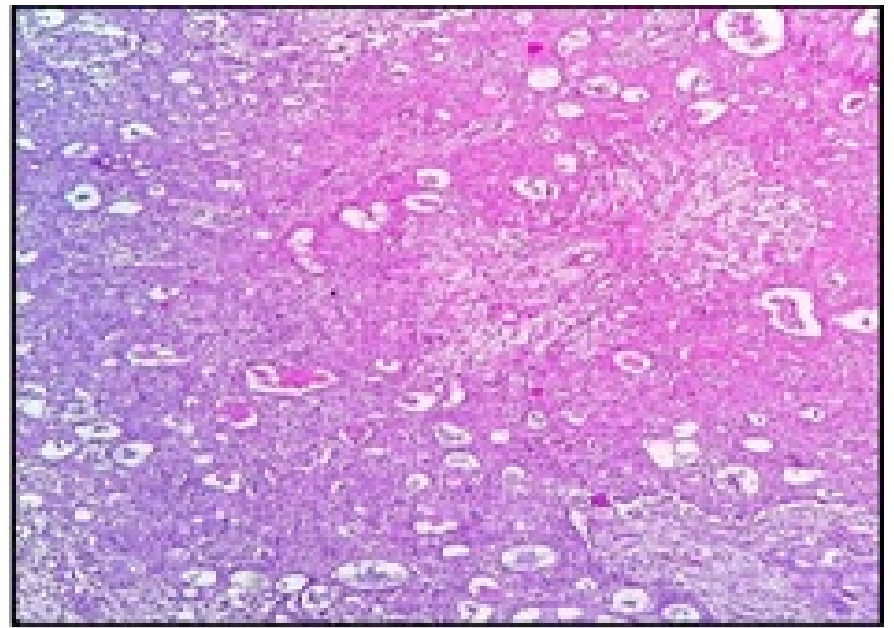

Fig-4: Photomicrograph Mucoepidermoid carcinoma: squamous, intermediate, and mucinous elements. (H and $E$ 40X).

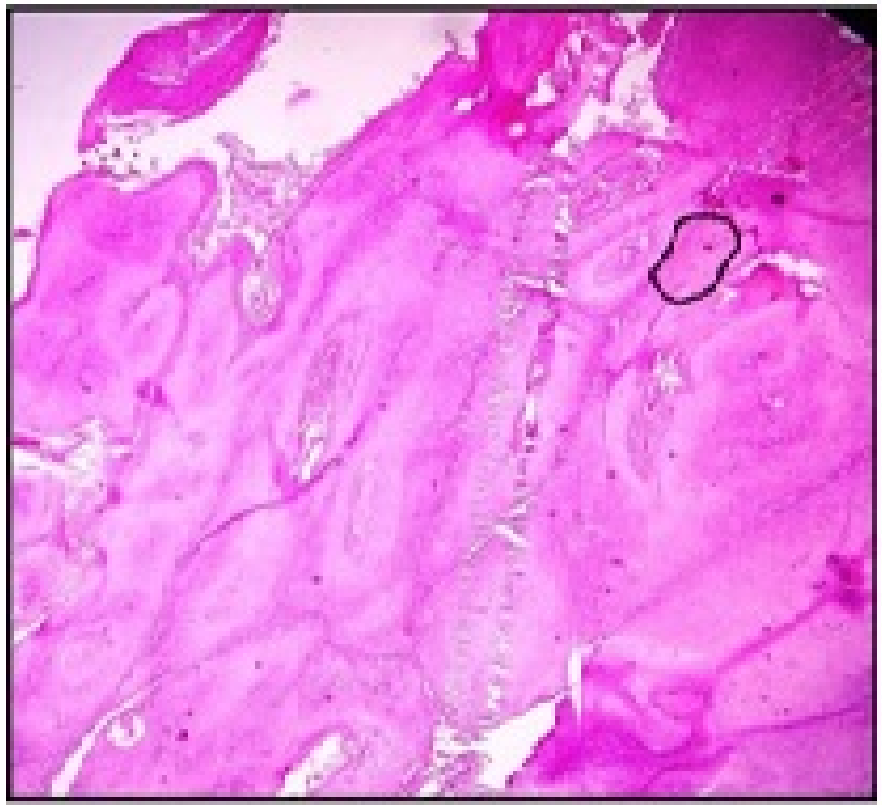

Fig-5: Photomicrograph showing verrucous carcinoma: bulbous rete pegs pushing into the underlying stroma ( $H$ and $E$ 40X). 
Site distribution of malignant lesions: In the present study the most common malignancy was Squamous cell carcinoma and site affected was buccal mucosa (16 cases), followed by the tongue (14 cases), lip ( 8 cases), retromolar trigone ( 7 cases), hard palate ( 6 cases), gingiva (5 cases) and floor of mouth (4 cases).
Among 5 cases of verrucous carcinoma, 3 were located in the buccal mucosa, and the remaining 2 were situated on the tongue. A case of each of sarcomatoid SCC, basaloid SCC and rhabdomyosarcoma was located on buccal mucosa. Both cases of NHL were located on the hard palate. Cases of mucoepidermoid carcinoma were located on buccal mucosa and hard palate each.

Table-3: Site distribution of SCC according to histological grade (Broder's grading).

\begin{tabular}{|l|l|l|l|l|}
\hline \multicolumn{1}{|c|}{ Site of lesion } & \multicolumn{1}{|c|}{ Grade I(WDSCC) } & Grade II(MDSCC) & Grade III(PDSCC) & Total \\
\hline Buccal mucosa & 15 & 1 & - & 16 \\
\hline Tongue & 11 & 3 & 0 & 14 \\
\hline Floor of mouth & 2 & 1 & 1 & 4 \\
\hline Retromolar trigone & 6 & 1 & & 7 \\
\hline Lip & 7 & 1 & - & 8 \\
\hline Hard palate & 5 & - & 1 & 6 \\
\hline Gingiva & 3 & 2 & - & 5 \\
\hline Total & 49 & 09 & 02 & 60 \\
\hline Percentage & $81.67 \%$ & $15 \%$ & $3.33 \%$ & $100 \%$ \\
\hline
\end{tabular}

Table 3 shows, Out of 60 cases of SCC, 49 $(81.67 \%)$ were well-differentiated, 9 were (15\%) moderately differentiated and only 2 (3.33\%) were poorly differentiated Squamous cell carcinoma.

Presenting symptoms: Ulcero-proliferative growth was the main presenting symptom in most malignant cases (53 cases; 73.61\%). Erythematous or white patch (20 cases), pain (19 cases), difficulty in chewing (18 cases), swelling (8 cases), and excessive salivation ( 7 cases) were the presenting symptoms in remaining cases.

Habits: In the present study of 100 cases, 83 patients gave a history of various habits like smoking, alcohol consumption, and smokeless tobacco in the form of Gutkha and khaini, pan eating (betel nut and lime) and combination of above. These habits were predominantly seen in males. Females were not involved in the habits of smoking and alcohol drinking. The habit of smoking was observed in 39 patients. Out of which 29 cases had malignant lesions.

50 patients gave the history of tobacco chewing, out of which 39 patients had a malignant lesion. It was observed that the habit of tobacco and pan chewing was common among females. A combined habit of smoking and alcohol consumption was observed in 14cases. A combined habit of smoking and smokeless tobacco consumption was observed in 15 cases. Out of 72 patients with malignant lesions, 10
Patients had no habits.

Histological typing of malignant lesions: In the present study squamous cell carcinoma was the most common malignancy comprising 60 cases $(83.33 \%)$. Next to squamous cell carcinoma was verrucous carcinoma (5 cases; 6.94\%). One case each of sarcomatoid squamous cell carcinoma, basaloid squamous cell carcinoma and rhabdomyosarcoma were studied. Two cases of lymphoma (NHL) and mucoepidermoid carcinoma were studied in the present study.

Distribution of benign lesions according to histological typing: In the present study 12 cases of benign lesions were studied, of which buccal mucosa and tongue were common sites accounting for $33.33 \%$ each. Squamous papilloma was the commonest benign lesion (41.67\%). Next was haemangioma (4 cases) and the commonest site was tongue. Two cases of granular cell tumors were studied, where buccal mucosa and gingiva were the common sites for each. One case of chondroma of hard palate was studied in the present study.

Sex wise distribution of benign tumors of the oral cavity: Present study of 12 cases of benign lesions Squamous cell Papilloma (5), haemangioma (4), granular cell tumor (2), chondroma (1) showed male preponderance with a male: female ratio of $2: 1$. 
Site wise distribution of tumor-like lesions of the oral cavity: In the present study 12 cases of tumor-like lesions were studied. Inflammatory lesions were the commonest tumor-like lesions. They were biopsied with clinical suspicion of malignancy. The lesions were located buccal mucosa, tongue, retromolar trigone, lip andgingiva.3 cases of granuloma pyogenic were situated on the buccal mucosa, lip, and gingiva.

Sex wise distribution of tumor-like lesions of the oral cavity: Tumour like lesions showed male preponderance with a male: female ratio of 3:1.Inflammatory lesions and dermoid cysts were exclusively seen in males in the present study. Granuloma pyogenic was seen only in females.

\section{Discussion}

Higher incidence in developing countries like India is attributing to risk factors like the habit of tobacco chewing, betel nut and alcohol consumption, poor oral hygiene, and less intake of fruits [4].

In our study, we found 72 (72\%) malignant cases, $12(12 \%)$ benign lesions, 12 (12\%) tumors like lesions, and 4 (4\%) epithelial precursor lesions. This is comparable with the above studies of Parikins et al [5], Gupta et al [17], and Atram et al[18], which also show similar findings with our study in which incidence of malignant lesions is more than tumorlike and benign lesions. The present study is hospital-based and carried at a tertiary care center. So that mostly malignant cases being referred at our hospital.

In the present study, peak age incidence was noted in the 6 th decade with the youngest patient of 5 years of age and the oldest of 84 years old. These findings are consistent with Khandekar et al [10] and Masamatti et al [16]. These findings are also consistent with Mehrotra et al [2], Parikh et al [13],
Gupta et al [17], Manjit Singh Bal [15] and Ray et al [7], Parkins et al [5] noted in their study that maximum cases occurred in the 4th-7th decade. In the present study out of 72 malignant cases, 49 were male and 23 female with a male: female ratio of $2.1: 1$. This is consistent with Parkins et al [5],Gupta et al [17], and Atram et al [18] which show male: female ratio of 2.3: $1,2.1: 1$, and 2.7:1 respectively.

In the present study, the most common site for malignant lesions was buccal mucosa. This finding is consistent with Parikh et al [13] and Gupta et al [17]. However in the study of Atram et al [18], the most common site was tongue. The difference might be due to the different habits of tobacco chewing.

In the present study, the most common presenting complaint was Ulcero-proliferative growth (53 cases) followed by erythematous/leukomatous patch (20), pain (19 cases), difficulty in chewing (18). Some patients also gave a history of swelling and excessive salivation. In the study of Parkins et al [5], the main presenting complaint was mandibular facial swelling $(63 \%)$, followed by intraoral swelling $(55 \%)$, pain $(41 \%)$. Some patients also presented with ulceration, loosening of teeth.

In the study of N. Riaz [6], mandibular facial swelling (63\%), intra-oral swelling (55\%), and

Ulceration of the oral cavity (29\%) were the main complaints. Gupta et al [17] stated growth (73.5\%), ulcer $(35 \%)$, and pain $(12.5 \%)$ as the main presenting complaints in their study. In the study of Masamatti et al [16] Ulcero-proliferative growth was the main presenting symptom, followed by pain, difficulty in chewing. Some patients also presented with a white patch, swelling, mucosal irregularities, and excessive salivation. Thus, the present study is in accordance with Masamatti et al [16] and Gupta et al [17].

Table No. 5: Comparison of malignant lesions according to various habits/ risk factors.

\begin{tabular}{|l|l|l|l|l|l|}
\hline \multicolumn{1}{|c|}{ Habits } & \multicolumn{1}{|c|}{ Khandekar et al [10] } & Agrawal et al [11] & \multicolumn{1}{|c|}{ N. Rajesh et al [14] } & \multicolumn{1}{c|}{ Gupta et al [17] } & \multicolumn{1}{c|}{ Present study } \\
\hline Alcohol & - & & $20(16.6)$ & $4(2)$ & $13(18.05)$ \\
\hline Smoking & $31(63.3)$ & $22(13.75)$ & $42(35.8)$ & $51(25.5)$ & $29(40.2)$ \\
\hline Tobacco & $57(71.3)$ & $75(47)$ & $98(81.6)$ & $38(19)$ & $39(54.16)$ \\
\hline Betel nut & & & $51(42.5)$ & - & $13(18.05)$ \\
\hline Alcohol+Smoking & - & $30(18.75)$ & & $16(8)$ & $11(15.27)$ \\
\hline Smoking+tobacco & $18(22.5)$ & $12(7.5)$ & & $10(5)$ & $12(16.67)$ \\
\hline
\end{tabular}


Tobacco consumption is a very significant risk factor for oral cancers. Other risk factors are age and male sex. The risk increases further when combined with

Alcohol. In the present study number of patients gave a history of tobacco consumption in the form of smoking or smokeless tobacco i.e. tobacco chewing. This finding was observed by other workers also.

In the present study, $81.67 \%$ of cases of welldifferentiated (Grade I) squamous cell carcinoma, $15 \%$ of cases of moderately differentiated SCC, and $3.33 \%$ poorly differentiated SCC were observed. These findings are consistent with the findings of Atrametal [18].

In the present study, the most common malignancy was squamous cell carcinoma (83.33\%), followed by verrucous carcinoma (6.94\%). We found 1 case $(1.38 \%)$ each of the basaloid variant of squamous cell carcinoma, a spindle cell variant of squamous cell carcinoma and rhabdomyosarcoma. 2 cases $(2.78 \%)$ each of mucoepidermoid carcinoma and Non-Hodgkin's lymphoma were studied. Ahluwalia et al [9] studied 2232 malignant cases of the oral cavity in which they found 2066 cases of SCC, 40 cases of the basaloid variant of squamous cell carcinoma, 4 cases each of lymphoma and mucoepidermoid carcinoma. They also found cases of basal cell carcinoma (66 cases), giant cell tumor ( 2 cases), adenoid cystic carcinoma ( 5 cases).

In the study of Parkins et al [5] most common malignancy was SCC $(62 \%)$, followed by lymphoma $(19 \%)$. They also studied cases of MEC $(1 \%)$, chondrosarcoma (3\%), adenocarcinoma (3\%), spindle cell carcinoma (3\%), ameloblastic carcinoma $(1 \%)$ and plasmacytoma (1\%). The incidence of NHL was higher in the study of Parkins et al (19\%) due to the higher prevalence of Burkitts Iymphoma in Ghana.

In the study of $\mathrm{N}$. Riaz et al [6] most common malignancy was SCC (\%), followed by salivary gland malignancies $(16.1 \%)$. They also studied cases of chondrosarcoma (2\%), rhabdomyosarcoma (5.3\%), spindle cell carcinoma (3\%), ameloblastic carcinoma $(1 \%)$, and osteosarcoma (3.2\%). Parikh et al [13] studied 81 cases of malignant lesions.

They found 71 cases of SCC, 7 cases of verrucous carcinoma, one case each of papillary SCC, adenoid cystic carcinoma and spindle cell sarcoma. In the study of Masamatti et al [16] SCC was the commonest malignancy (92.74\%) followed by
Verrucous carcinoma (4.55\%). They also studied papillary carcinoma $(0.60 \%)$, basaloid SCC $(1.21 \%)$, spindle cell SCC $(0.60 \%)$. Gupta et al [17] studied 162 cases of SCC, 2 cases of MEC, and 1 case of adenoid cystic carcinoma. Atram et al [18] studied 144 malignant cases. SCC was the commonest malignancy (135 cases). They also found 5 cases of verrucous carcinoma, 2 cases each of basaloid SCC, and rhabdomyosarcoma.

In the present study 4 cases of dysplasia were studied. Peak age incidence in the 5th decade was noted. All 4 cases were male. The most common site as buccal mucosa followed by tongue and gingiva. Clinically the lesion was presented as white (leukoplakia) or red (erythroplakia) patch.

In the present study incidence of premalignant lesions was $4 \%$. This correlates with studies of Parikh et al [13], Masamatti et al [16], and Gupta et al [17]. A higher incidence was noted in the study of Mehrotra et al [2] (29.89\%). In the study of Mehrotra et al [2] among 344 cases of premalignant lesions, $73.2 \%$ were male and $26.7 \%$ were females. Gupta et al [17] studied 8 cases of premalignant lesions.

The peak age of incidence was in the 5th decade. 6 cases were makes and 2 were females, the most common site of involvement was buccal mucosa. In the study of Masamatti et al [16] 30 cases of premalignant lesions were studied, 19 were males and 11 were females with peak age incidence in the 5 th decade. Clinically these lesions were presented as mucosal irregularities and white patches. The most common site of involvement was buccal mucosa followed by tongue.

The present study was hospital-based and not community-based.

Hence results may vary due to patient selection bias. In the present study we studied 12 benign lesions, most common benign lesion was squamous papilloma (5 cases, $41.67 \%$ ) followed by haemangioma (4 cases, 33.33\%). Two cases of granular cell tumors and one case of chondroma of hard palate were studied. Parikh et al [13] found 3 benign lesions, 2 cases of squamous papilloma, and 1 case of Neurofibroma.

Gupta et al [17] found 5 cases of squamous papilloma, 3 cases of haemangioma, 2 cases of pleomorphic adenoma, and 1 case of basal cell adenoma, fibroma, lipoma, Neurofibromaandschwannoma. Atram et al [18] 
Studied 10 cases of haemangioma, 2 cases of squamous papilloma, and 1 case each of lipoma, Neurofibroma, schwannoma, and nevus. The lesion was associated with cleft palate.

A case of Soft tissue chondroma of hard palate was reported by Paolo Vescovi et al [19], 63 years old man presented with long-standing painless swelling on the hard palate. The study of the youngest patient (7-year-old male) presented with Granuloma

Pyogenic of the upper lip and the oldest patient ( 80 years old male) with a mucous retention cyst of the buccal mucosa. Our hospital is tertiary care Centre and mostly malignant cases were referred to our institute. Therefore, the incidence of benign lesions may vary.

In the present study 12 cases of the tumor-like lesion were studied. The most common lesion was non-specific inflammation (6 cases) and 3 cases each of the dermoid cyst and granuloma pyogenic. Manjit Singh Bal et al [15] studied 22 cases of granuloma pyogenic and 13 cases of non-specific inflammation.

\section{Limitations of the study}

Ours is the hospital-based study and not community-based, therefore incidence may vary

Due to patient selection bias. Also, patients were lost to follow up. So that prognosis of the individual lesion in our study was not studied.

\section{Conclusions}

In the present study Squamous cell carcinoma has emerged as a most common malignancy leading to morbidity and mortality; an effective preventive and curative measure is the need for time for preventing its threat to the community. Hence Histopathological examination is required for confirmation. The present study was conducted at a tertiary care center where the bulk of patients are from the periphery and rural areas.

Late presentation to health care centers was observed due to lack of awareness, negligence, and preference for age-old traditional remedies of treatment. It is the need of the hour to create awareness among people about an early approach to hospital, maintenance of oral hygiene by cultivating good oral habits, and periodic oral checkups.

\section{What does the study add to the existing knowledge?}

The proportion of oral cavity lesions is also increasing among young adults due to habits of tobacco chewing, Gutkha, and smoking. There is a need to educate youngsters by using social media platforms to inoculate healthy lifestyles. The role of NGOs and the government will play a vital and crucial role in the long term for controlling lesions of the oral cavity.

\section{Author's contribution}

Dr. Shaikh Parvin Abdul Rauf: Principle author, collected data and has written the manuscript.

Dr. Bharat R Sonwane: The corresponding author, edited the article and has written the discussion and performed data analysis.

\section{Abbreviations}

BSCC: Basaloid variant of squamous cell carcinoma; DPX: Distyrine plasticizer xylene

GCT: Granular cell tumour; HPV: Human Papilloma Virus; HHV: Human Herpes virus

IARC: International Agency for Research On cancer; KS: Kaposi's sarcoma; LKP: Leukoplakia

MEC: Mucoepidermoid carcinoma; $\mathrm{n}$ : Number; No.: Number; NHL: Non-Hodgkin Lymphoma

OSF: Oral submucous fibrosis; RMS: Rhabdomyosarcoma; SPCC: Spindle cell variant of squamous cell carcinoma

SCC: Squamous cell carcinoma; WHO: World Health Organization.

\section{Reference}

01. Mitra SK, Misra RK, Rai R, Rai P, Arya ML. Study of expression patterns of cytokeratin 8 and 18 in oral cancers. Trop J Pathol Microbiol. 2016;2(3)83-88.

Available from:

[Article:https://pathology.medresearch.in/index.php/j opm/article/view/19][Crossref]

02. Subhe N, Ali E, Hassawi BA. Tumors and Tumor like lesions of the Oral Cavity- A Study of 303 Cases. Med J Tikrit. 2010;1(161)177-183. [Crossref] 
03. Riaz N, Warriach RA. Tumors and Tumour- Like Lesions of the Oro - Facial Region at Mayo Hospital, Lahore - A Five Year Study. Annals of King Edward Med University. 2011;17(2)123129.

doi:

[Article:https://doi.org/10.21649/akemu.v17i2.285] [Crossref]

04. Pires FR, Ramos AB, Bittencourt J Oliveira C De, Tavares AS, et al. Oral squamous cell carcinoma- clinicopathological features from 346 cases from a single Oral Pathology service during an 8-year period. J Appl Oral Sci. 2013;21(5)460-467.

doi: [Article:http://dx.doi.org/10.1590/1679775720130317][Crossref]

05. Mehrotra R, Pandya S, Chaudhary AK, Kumar M, Singh M. Prevalence of oral pre-malignant and malignant lesions at a tertiary level hospital in Allahabad, India. Asian Pac J Cancer Prev. 2008;9(2)263-265.

[Crossref]

06. Grace EA Parkins, G Armah, Patrick A. Tumours and tumourlike lesions of the lower face at Korle Bu Teaching Hospital, Ghana - an eight-year study. World J Surg Oncol. 2007;5(48).

doi: [Article:https://doi.org/10.1186/1477-7819-548][Crossref]

07. Neville BW, Day TA. Oral cancer and precancerous lesions. CA- Cancer J Clinic. 2002;52(4)195-215.

doi:

[Article:https://doi.org/10.3322/canjclin.52.4.195]

[Crossref]

08. Ray JG, Ganguly M, Rao BHS, Mukherjee S, Mahato B. Clinico - epidemiological profile of oral potentially malignant and malignant conditions among areca nut, tobacco and alcohol users in Eastern India- A hospital-based study. J Oral Maxillofac Pathol. 2013;17(1)4550.

doi: [Article:http://dx.doi.org/10.4103/0973029X.110720][Crossref]

09. Ahluwalia H, Gupta SC, Singh M, Mishra V, Singh PA, Walia DK. Spectrum of Head and Neck Malignancies in Allahabad. Indian J Orolaryngol Head Neck Surg. 2001;53(1)16-21.

doi: [Article:http://dx.doi.org/10.1007/BF02910972] [Crossref]
10. Khandekar SP, Bagdey PS, Tiwari RR. Oral Cancer and Some Epidemiological Factors- A Hospital Based Study. Indian J Community Med. 2006;31(3)157-159.

[Crossref]

11. Agrawal, $\mathrm{KH}$, Rajderkar S. Clinicoepidemiological profile of oral cancer- A hospital based study. Indian J Comm Health. 2012;24(2)80-84.

Available

from: [Article:https://www.iapsmupuk.org/journal/index.ph p/IJCH/article/view/227][Crossref]

12. Vescovi P, Meleti M, Merigo E, Manfredi M, Corradi D, Giovannacci I, et al. Soft tissue chondroma of the oral cavity- an extremely rare tumour localized on the hard palate. Case Reports Med. 2014.

doi: [Article:https://doi.org/10.1155/2014/414861] [Crossref]

13. Gupta M, Choudhary H, Gupta N, Gupta A. Histopathological study of neoplastic lesions of oral cavity and oropharynx. Int J Res Med Sci. 2016;4(5)1506-1510.

doi: [Article:http://dx.doi.org/10.18203/23206012.ijrms20161219][Crossref]

14. Bal MS, Jain A, Bodal VK, Kaur J, Sohal BS, Suri $A K$, et al. A Clinico-Pathological Study of 200 Cases of Oral Cavity Lesions. Res J Pharma Biol Chem Sci. 2014;5(6)1035-1040. [Crossref]

15. Masamatti SS, Gosavi AV. Histopathological Study of Malignant Oral Tumors- A Five-Year Study. Int J Sci Stud. 2016;4(3)30-34. doi:

[Article:http://dx.doi.org/10.17354/ijss/2016/312] [Crossref]

16. Rajesh N, Sreelakshmi K, Ramesh K. Profile of Oral Cancer Patients Attending Tertiary Care Centre, Bellary, Karnataka, India. Int J Curr Res Aca Rev. 2014;2(8)46-52.

[Crossref:Crossref]

17. Atram MA, Bhalavi V, Dantkale S. A Clinicopathological study of tumors and tumor like lesions of oral cavity. Indian J Bas App Med Res. 2016;5(3)146-153.

[Crossref] 
18. Mehta NV, Dave KD, Gonsai RN, Goswami HM, Patel PS, Kadam TB. Histopathological Study of Oral Cavity Lesions- A Study On 100 Cases. Int J Cur Res Rev. 2013;5(10)110-116.

[crossref]

19. Parikh S, Prajapati H, Shah NR. Histopathological Study of Oral Cavity Lesions. Int J Sci Res. 2013; 2(11)430-432.

[Crossref:Crossref] 